\title{
Understanding the role of organizational legitimacy within the realm of the community-based conservation approach
}

\author{
Armand Randrianasolo', Arilova A. Randrianasolo"
}

\author{
Correspondence: \\ Armand Randrianasolo \\ Missouri Botanical Garden \\ William L. Brown Center \\ P.O. Box 299 \\ St. Louis, Missouri 63166-0299, USA \\ Email: armand.randrianasolo@mobot.org
}

\begin{abstract}
Many organizations throughout the world utilize community based conservation (CBC) strategies to incorporate rural communities into conservation efforts. One key component to the success of these strategies is to gain trust within the communities which reside in the vicinity of the targeted areas for conservation. The research reported here introduces the concept of organizational legitimacy into the realm of $\mathrm{CBC}$ strategy by proposing how dimensions of legitimacy (pragmatic, moral, and cognitive) are related to community trust and attitudes. Employing institutional theory, this paper proposes that (i) pragmatic and moral legitimacy produce trust, (ii) trust positively influences cognitive legitimacy, and (iii) cognitive legitimacy influences attitudes. The Missouri Botanical Garden's (MBG) CBC efforts in Madagascar's Ambalabe and Mahabo communities served to empirically examine these propositions. The survey yielded 101 usable responses from community members in Mahabo and Ambalabe. A structural model was estimated to test the propositions and the results provided support for the premise that organizational legitimacy is needed to gain trust and influence favorable attitudes toward the organization. Since $\mathrm{CBC}$ strategies rely on trust between organizations and communities, the findings of this research provide implications for organizations seeking to implement CBC strategies. The findings do so by implying that in order to build trust with communities, organizations should first establish legitimacy, which not only helps build trust, but also indirectly affects attitudes toward the organization and its activities.
\end{abstract}

\section{RÉSUMÉ}

De nombreuses organisations à travers le monde utilisent les stratégies de la conservation communautaire pour intégrer les communautés rurales dans les efforts de conservation. Un élément clé du succès de ces stratégies est de gagner la confiance des communautés qui résident dans les zones ciblées. La présente recherche introduit le concept de légitimité organisa- tionnelle dans le domaine de la stratégie de conservation communautaire en indiquant comment les dimensions de la légitimité (pragmatique, morale et cognitive) influencent la confiance et les attitudes de la communauté. Utilisant la théorie institutionnelle, ce document propose que (i) la légitimité pragmatique et morale entraîne la confiance, (ii) la confiance influence positivement la légitimité cognitive, et (iii) la légitimité cognitive prédit les attitudes. Afin d'examiner empiriquement ces propositions, les efforts déployés par le Missouri Botanical Garden dans les communes d'Ambalabe et de Mahabo à Madagascar ont été utilisés pour collecter les données. Cette technique d'échantillonnage a donné 101 réponses utilisables venant des membres des communautés des deux communes. Un modèle structurel a été estimé pour tester les propositions et les résultats obtenus et soutient I'hypothèse selon laquelle la légitimité organisationnelle est nécessaire pour gagner la confiance et susciter des attitudes favorables à l'égard de l'organisation. Puisque les stratégies de conservation communautaire s'appuient sur une relation basée sur la confiance entre les organisations et les communautés, les résultats de cette recherche montrent que si des organisations cherchent à mettre en œuvre des stratégies de conservation communautaire, elles doivent d'abord établir leur légitimité afin de gagner la confiance des communautés respectives.

\section{INTRODUCTION}

For the past several decades, conservation research has highlighted the importance of community based conservation (CBC) (Parker 1983, Owen-Smith 1993, Western and Wright 1994, Hackel 1999, Berkes 2004, Fritz-Vietta et al. 2009, Brooks et al. 2013). CBC is a strategy utilized by organizations around the world to conserve environments by actively working with local people in the targeted areas of conservation (Hackel 1999, Waylen et al. 2010). This approach allows the organization to not only incorporate the interests of the local people, but also engage the people into an integrated conservation strategy. In other words, the main idea
I

Citation 
behind $\mathrm{CBC}$ is that both conservation and development can be simultaneously attained, which serves the interests of both the community and the organization (Berkes 2004). For example, in 2003, Blue Ventures, a U.K.-based conservation organization, had interests in conserving marine life in southwestern Madagascar, a region where coral reefs were deteriorating due to factors such as the exacerbated commercialisation of traditional fisheries by exporters and climate change (Harris 2007, 2011). To satisfy this interest, Blue ventures has worked with local fishermen in establishing a 'no take zone', where fishing restrictions were put in place to improve the sustainability of reef octopus (Harris 2007). In this case, Blue Venture's sustainable community-based system not only satisfied the interests of local people in terms of higher fishing profits and sustainable fishing practices, but also involved fishermen into an integrated marine life conservation strategy. $\mathrm{CBC}$ strategies thus rely on the integration of local communities into conservation strategies in order to satisfy the interests of both the organization and the local communities.

This method has been utilized in numerous conservation projects, and conservation research has discussed the positive effects of gaining trust through the CBC method (e.g., Mehta and Heinen 2001, Goldman 2003, Waylen et al. 2010). However, this extant research has relatively ignored the question of how to gain this trust. Researchers have depicted the attitudinal and behavioural effects of the CBC method (e.g., Mehta and Heinen 2001, Waylen et al. 2010), however, the question of what predicts the success of $\mathrm{CBC}$ efforts remains unanswered. In this current paper, we aim for a better understanding of the requirements of $\mathrm{CBC}$ success by proposing the role which organizational legitimacy plays in this dynamic. Since CBC is driven by the interest of local people as well as an organization's conservation targets (Campbell and Vainio-Mattila 2003), we envision CBC success to be the strategy's effectiveness in achieving such objectives. We thus define CBC success to be the fulfilment of community interests as well as the attainment of the organization's conservation goals through a collaborative relationship between the organization and the community. Here we seek to better understand the role of organizational legitimacy in contributing to CBC success by investigating its role for the organization in gaining trust and favourable attitudes from local people.

Furthermore, in spite of the rise in $\mathrm{CBC}$ implementation around the world, relatively little research has been conducted to investigate the cognitive network of constructs relevant to $\mathrm{CBC}$ strategies from the perspective of local community members. To address this concern, researchers like Waylen et al. (2010) have taken a perspective focused on local cultural contexts to examine how local attitudinal and behavioural dispositions indicate the outcomes of CBC efforts. In an effort to build on this previous research, we introduce the concept of organizational legitimacy into the realm of $\mathrm{CBC}$ strategies and its attitudinal outcomes within local cultural contexts. Organizational legitimacy has to be considered within the local cultural context, as local institutions provide the norms of what is socially acceptable and what is not acceptable to the community. Within this current paper, we utilize the term institution to refer to the "regulative, normative, and cognitive structures and activities that provide stability and meaning to social behaviour" (Scott 1995: 33). Institutions are the informal norms as well as the formal laws which provide structure to an environment (Peng et al. 2009). They are the formal and informal constraints that shape human interaction (Berkes 2004). Similarly, we utilize the term community to describe a group of people who are socially interdependent, share practices, and exist in an environment in which people interact in a cohesive manner (Bellah et al. 1985, Rovai 2002). We use the term organization to refer to a formal entity within an environment that has a specific purpose. This definition of organization is derived from the perspective of strategic management research (e.g. Mintzberg 1987). Finally, we use the term institutional environment to refer to the environment in which community members and organizations coexist and are governed by institutions (Scott 1995). For an organization to achieve its purpose, it must first gain legitimacy, or acceptance, within its institutional environment (Kostova and Zaheer 1999).

since legitimacy is defined as the social acceptance of an organization within its local institutional environment (DiMaggio and Powell 1983, Suchman 1995), we envision this construct to play a pivotal role in the conceptual and strategic understanding of how organizations gain trust through $\mathrm{CBC}$ strategies and influence attitudes. Thus, we propose and empirically examine a conceptual framework that incorporates 'legitimacy', 'trust', and 'attitudes'.

Utilizing the context of Missouri Botanical Garden's (MBG) $\mathrm{CBC}$ efforts in Madagascar, we examine how levels of organizational legitimacy influence trust for the MBG (the organization) within the rural communities of Ambalabe and Mahabo in Madagascar, two of the twelve MBG conservation sites where CBC has been implemented. The impact of this study touches on the strategic implication of how organizations can gain trust within communities they are interested in collaborating with. Since trust is an important component in establishing CBC strategies, as mentioned by Berkes (2007), the results of this research are thus relevant to organizations seeking to implement the CBC method. In other words, by gaining an understanding of how organizational legitimacy influences trust and attitudes, organizations will be better prepared to implement legitimacy-seeking strategies when entering new areas of conservation. This study thus has two objectives: (i) to theoretically propose a model that incorporates the relationships between trust, legitimacy, and attitudes; and (ii) to empirically test this model in the context of an organization that has implemented the CBC method. In order to achieve these two objectives, we utilize two sites where MBG has implemented $\mathrm{CBC}$ efforts in Madagascar to measure legitimacy, trust, and attitudes; and then test the relationships between these constructs in a structural model. The following sections, first, review the background literature on $\mathrm{CBC}$, organizational legitimacy, attitudes, and trust; and, then, empirically examine a structural model of these relevant constructs.

\section{BACKGROUND AND THEORY}

Gaining trust within communities is a fundamental task that organizations seeking to implement conservation activities in rural areas face (Dolch et al. 2015). Within the past decades, many organizations have taken the approach to involve rural community members in sustainable resource planning and management, or $\mathrm{CBC}$, to address this challenge. $\mathrm{CBC}$ typically has two main objectives as described by Campbell and Vainio-Mattila (2003): to enhance biodiversity conservation and to provide incentives, which are often economic, to local people. The premise of the $\mathrm{CBC}$ method states that in order to effectively carry out conservationrelated activities, organizations must build trust with local communities (Berkes 2007). We propose that organizational legitimacy is a crucial component in building trust within local communities. 
ORGANIZATIONAL LEGITIMACY. Organizational legitimacy is the social acceptance of an organization by its environment (Suchman 1995). It refers to the social justification of an actor or activity as well as addresses the normative and cognitive forces that construct and empower organizational factors, and it is the acceptance of the organization by the society in which it exists (Suchman 1995, Kostova and Zaheer 1999, Sandström et al. 2014). It thus reflects the cultural support for an organization (Meyer and Scott 1983, Johnson et al. 2006). Organizational legitimacy has been stated to have three dimensions: pragmatic, moral, and cognitive legitimacy (Suchman 1995, Johnson et al. 2006). Pragmatic legitimacy refers to the "self-interested calculations of an organization's most immediate audiences" (Suchman 1995: 578). This form of legitimacy refers to the constituent's actual evaluation of an organization's actions where organizational behaviour is scrutinized to determine the practical consequences of the actions to the constituent (Wood 1991, Garud et al. 2014). Pragmatic legitimacy concerns the immediate, direct, and practical benefits which appeal to the legitimizing actor (Suchman 1995). Unlike pragmatic legitimacy, moral legitimacy is a positive normative evaluation of the organization's activity (Suchman 1995). The issue is not concerned about whether the activity benefits the evaluator, but rather if the activity is the right thing to do. Moral legitimacy, thus, is a reflection of whether the activity promotes social welfare, as defined by the constituent's socially constructed value system in the given institutional context (Suchman 1995). Cognitive legitimacy involves either affirmative backing for an organization or the mere acceptance of the organization as necessary or inevitable. It refers to the constituent's acceptance of the organization as a permanent part of its society (Suchman 1995). These dimensions of legitimacy are important to organizations seeking to achieve their objectives in the given environments because gaining legitimacy from a society leads to decreases in costs associated with operating in a foreign environment, as well as favourable attitudes toward the organization (Campbell et al. 2012, Husted et al. 2016). Pragmatic and moral legitimacy may be gained relatively quickly, however, cognitive legitimacy may only be gained after the legitimacy-granting constituent grants trust to the organization, and thus accepts the organization as part of its society (Suchman 1995).

TRUST. Trust is a construct that has elements of expectation and it exists within environments characterized by uncertainty. It is positive and is situation-specific (Bhattacharya et al. 1998). From this view, we adopt the definition of trust from Bhattacharaya et al. (1998), which states that trust is "an expectancy of positive (or nonnegative) outcomes that one can receive based on the expected action of another party in an interaction characterized by uncertainty" (Bhattacharya et al. 1998: 462). From this definition, we posit that community trust for an organization is thus a community's expectation of positive outcomes that can be received from an organization. Developing trust between an organization and the local community is a necessary condition for the effective implementation of CBC methods (Frey and Berkes 2014). We propose that in order for organizations to gain this trust, they may need to first gain pragmatic and moral legitimacy in the environment. We employ institutional theory (Scott 2008) to propose the predictive nature of legitimacy on trust.
THEORETICAL CONCEPT OF DEVELOPING LEGITIMACY, TRUST, AND POSITIVE ATTITUDES TOWARD THE ORGANIZATION. Institutional theory states that within an organization's environment, there are institutions that govern appropriate behaviour (Scott 2008). Institutions are formal or informal rules and norms that govern the behaviour of individuals and organizations within an environment (Allard and Small 2013). For example, in their study of community-based natural resource management in Madagascar's Manambolomaty Lakes, Rabearivony et al. (2008) emphasize the importance of understanding informal institutional norms that can contribute to the achievement of conservation objectives. In other words, understanding the local institutional environment is crucial to reaching conservation objectives.

In order for an organization to persist and thrive within an institutional environment, it must first be granted legitimacy from members of the environment such as the local people (Meyer and Rowan 1977, DiMaggio and Powell 1983, Osei-Tutu et al. 2014). According to institutional theory, legitimacy is granted within the contexts of the governing institutions (Meyer and Rowan 1977, Osei-Tutu et al. 2014). From this theoretical perspective, we propose that in order for organizations to gain a community's expectation of positive outcomes that can be received from the organization in the institutional environment (trust), constituents within the environment must either recognize the practical benefits the organization provides to the environment (pragmatic legitimacy) or the constituent must recognize the organization as morally good (moral legitimacy). Thus, our first hypothesis $\mathrm{H} 1$ is that both pragmatic and moral legitimacy positively influence community trust in the organization.

In this current paper, we do not propose cognitive legitimacy to constitute trust, but instead propose that trust predicts cognitive legitimacy. Specifically, we propose that once organizations meet a community's expectation of positive outcomes, i.e., are trusted, the community can begin to view the organization as a long-term or permanent part of their environment. Before a community can accept the organization as a permanent part of their environment, they must first develop trust for the organization. Thus, our second hypothesis $\mathrm{H} 2$ is that trust positively influences cognitive legitimacy.

Having cognitive legitimacy within a community is crucial for the organization in order to influence positive evaluations of the organization by the community. From this theoretical stance, we propose that a community's acceptance of the organization as a permanent part of their society, or cognitive legitimacy, influences positive attitudes toward the organization. The theoretical logic here is that since attitudes are the "summary evaluations of objects, issues, or people based on behavioural, cognitive and affective information or experiences" (Pirsch et al. 2007: 131), we propose that a community's acceptance of an organization's permanence within its environment, or cognitive legitimacy, contributes to the cognitive information concerning the organization, and in turn positively influences attitudes toward the organization. Thus, our final hypothesis $\mathrm{H} 3$ is that cognitive legitimacy positively influences attitudes toward the organization.

Understanding attitude formation within a community is crucial to organizational success because attitudes are a pre-disposition to behaviour (Bagozzi 1992). Consistent with this perspective, psychology research states that there is a hierarchical nature between attitudes and behaviour through the theory of reasoned action (e.g., Ajzen and Fishbein 1980, Smetana and Adler 1980). 
The theory of reasoned action states that attitudes influence behaviours and behavioural intentions (Ajzen and Madden 1986). Thus, understanding the constructs that influence attitudes would provide organizational guidance in predicting behavioural reactions to an organization's strategies in their respective community. From the theoretical premise of institutional theory and the theory of reasoned action, we propose a model of legitimacy, trust, and attitudes.

In summary, our conceptual framework incorporates four elements: (i) we adopt a multidimensional perspective of legitimacy, (ii) we propose that two dimensions of legitimacy (pragmatic and moral) influence trust, (iii) we propose that trust influences cognitive legitimacy, and (iv) we propose that cognitive legitimacy influences attitudes. This framework is important to the implementation of the CBC method since attitudes and trust constitute two components to CBC success, as mentioned by previous research (i.e., Salafsky et al. 2001, Lepp and Holland 2006). Thus, this theoretical framework allows for an increased understanding of trust-building and attitude formation by proposing the role of legitimacy in this network of constructs; a perspective that can be useful for organizations seeking to implement $C B C$ strategies. An example of an organization that has implemented the $\mathrm{CBC}$ strategy and gained legitimacy from local environments is the Missouri Botanical Garden (MBG), as discussed in the following section.

\section{MBG IN MADAGASCAR: AMBALABE AND MAHABO CONSERVATION SITES}

MBG is a private, not-for-profit scientific institution based in St. Louis, Missouri, USA. It was founded in 1859 by Henry Shaw (1800-1889) to provide recreational and aesthetic benefits of nature to the city's residents, and to contribute to expanding and applying knowledge about the natural world. Currently, MBG's activities span a wide range including horticultural displays, public instruction and outreach, plant conservation, and botanical research (MBG 2017). In keeping with its mission statement, "To discover and share knowledge about plants and their environment in order to preserve and enrich life", MBG's conservation and research programs are international in scope, with activities across every continent. The Garden's herbarium is now among the largest in the world, with over 6.6 million specimens (MBG 2017). One country that has been of particular interest to the MBG's conservation efforts is Madagascar. Madagascar is one of the most ecologically diverse islands in the world, with numerous endangered and endemic species of flora and fauna (Lowry et al. 1997, Rakotomanana et al. 2013).

MBG has operated a multi-faceted program in Madagascar for more than three decades. Initially, it focused on documenting this island's remarkable plant diversity (e.g. Waeber et al. 2016), taxonomic research, and in-country capacity building, with special emphasis on training. In the early 2000s, MBG became directly involved in promoting the conservation of Madagascar's native plants due to the severity of the island's plant species decline. This involvement encompasses several elements: (i) the analyses of botanical information to assist in conservation planning and decision-making; (ii) the improvement of advocacy for the conservation of Malagasy plants; (iii) the species-focused conservation of plants on the brink of extinction; and (iv) the establishment of CBC activities at priority areas for plant conservation that have led to the establishment of a dozen new, officially recognized protected areas. Two of these recognized protected areas are the Ambalabe and Mahabo forests, as discussed below.

AMBALABE SITE. The Ambalabe Forest (known locally as the Vohibe forest) is located in the Ambalabe commune, District of Vatomandry, in the eastern part of Madagascar (Figure 1). This Forest has an area of 3,117 ha composed of mid and low elevation tropical rainforests with scattered patches of secondary forest and wooded grassland located in Madagascar's eastern escarpment. The Ambalabe Forest is home to 11 species of lemur, from which three species (Varecia v. variegata, Propithecus diadema, and Indri indri) are Critically Endangered (IUCN 2016). This forest also contains countless endemic plant species including species that are threatened (e.g., Dypsis faneva Beentje (Arecaceae), Dalbergia pupurascens Baill. (Fabaceae) according to IUCN Red List (IUCN 2016). MBG began working with the people of the overall Ambalabe commune, which includes all fokontany in the commune, in 2005, a time when the forest had not yet been scientifically explored, but was under a steady threat of human actions such as the traditional agriculture practice of slash and burn for rice farming. Part of the Ambalabe forest is classified as eastern lowland forest, a highly degraded ecosystem mainly due to slash and burn practices for rice cultivation in the eastern region of the island. To save the Ambalabe forest from destruction, as well as to contribute to the conservation of Madagascar lowland rainforest and the biodiversity it contains, MBG set up the $\mathrm{CBC}$ initiative in the Ambalabe Commune with the permission of the local authority and the members of the community.

MAHABO SITE. The Mahabo Forest (known locally as Ag nalazaha forest) is located at the Mahabo-Mananivo commune, District of Farafangana, in the southeastern region of Madagascar. The Mahabo forest has an area of 1,565 ha composed primarily of an evergreen humid forest on sand mixed with marshland and grassland vegetation. It is one of the best remaining Malagasy forest patches of the eastern littoral forests (Figure 2) with an approximate 5-38 $\mathrm{m}$ above sea level. The Mahabo forest is home to many endemic plant species such as Asteropeia micraster Hallier $\mathrm{f}$. and Leptolaena multiflora Thouars, respectively members of the endemic plant family Asteropeiaceae and Sar-

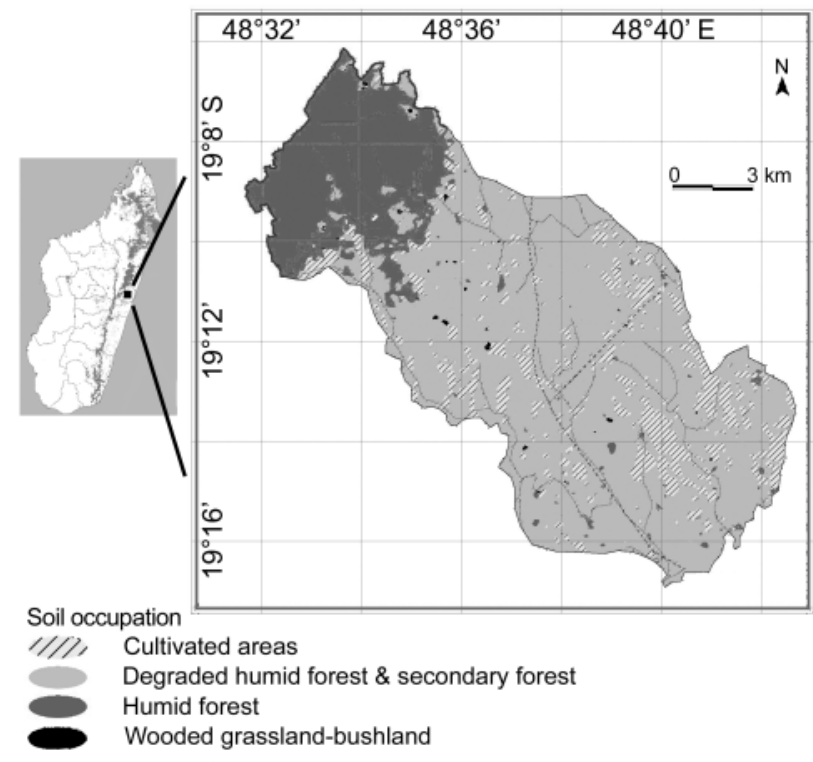

Figure 1. Ambalabe Forest. 


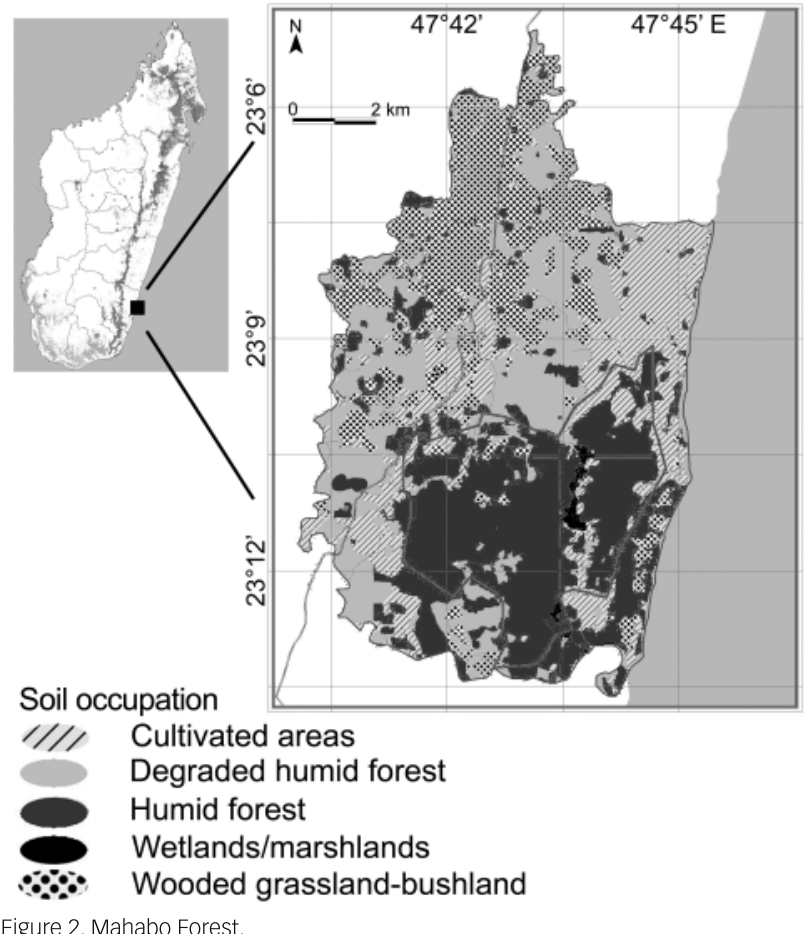

Figure 2. Mahabo Forest.

colaenanceae. These two species among several other species like Dalbergia louvelii R. Vig. (Fabaceae), Dypsis utilis (Jum.) Beentje \& J. Dransf. (Arecaceae), are threatened according to the IUCN Red List (IUCN 2016). This forest is also home to the Critically Endangered White-collared Brown Lemur (Eulemur cinereiceps) (Andriaholinirina et al. 2014) and other species of lemur such as Avahi laniger and Cheirogalus major. MBG began working with the overall Mahabo Commune, which includes all fokontany in Mahabo, in 2003 when the forest was highly threatened by unsustainable practices from the surrounding population (Andriamaharoa et al. 2010). The eastern littoral forest on sand is one of the most highly degraded and threatened ecosystems in Madagascar. This is due to its easy access by the surrounding population, which permanently alter the habitat through deforestation. A study by Consiglio et al. (2006) suggests that the eastern littoral forest habitats house approximately $13 \%$ of the estimated 12,000 Malagasy vascular plants.

In both the Mahabo and Ambalabe sites, the MBG has implemented the CBC strategy in an effort to conserve the remaining forests. The activities related to this strategy are discussed in the following sections.

CBC IN AMBALABE AND MAHABO. For MBG in Madagascar, it is customary practice when conducting either botanical/ ethnobotanical studies or conservation activities for the staff to initially conduct a courtesy visit with community/ village leaders in the area of interest. This must be done before carrying out any activity, and its purpose is to greet and explain the objectives of the visit to the community leaders. Through this conversation, the community leaders are asked if they can grant the MBG staff the permission to carry out their plans in the area. Gaining permission from community leaders minimizes the risks of any future misunderstandings. This approach was used in both Mahabo and Ambalabe.

After the initial meeting with community leaders at each site, a dialogue and consultation was conducted in the form of a work- shop within the community in order to build a relationship with the community members as well as to obtain information about each community's way of life, beliefs, goals, and relationships with the environment. This process provided the MBG staff members with the opportunity to inform community members about the importance of their participation in all aspects of the collaboration. Concurrently, the MBG staff was able to gain a better understanding of the issues between local communities and their environment, and the community members' interests. The ultimate result of the workshops at each site was that the MBG staff was able to have a clear vision of which activities to prioritize, with respect to both community and MBG interests. As a result, activities that have a positive direct impact on both forest conservation as well as improving the community's quality of life were prioritized.

It was only after these initial introductions with community leaders and workshops with the community members that the MBG staff was able to fully implement $\mathrm{CBC}$-centred activities in each site. These activities were divided in three interconnected categories: research, natural resource management, and socioeconomic development. In research, MBG staff members have been able to conduct botanical inventories and surveys to increase and improve the knowledge of the biodiversity of the two forest sites. Furthermore, ethnobotanical surveys at the two sites were conducted to document the traditional knowledge of plant use. The information obtained from these surveys and inventories helped shape the activities aimed at conserving the biodiversity of the two forested sites.

In terms of natural resource management, nurseries were established to produce either native species seedlings or non-native fast-growing tree plant species. The native species seedlings propagation was aimed at restoring forest patches that had been destroyed, while the non-native fast growing tree seedlings were distributed to community members to grow in their fields. This allows for an alternative solution to the problem of community members cutting down the native trees from the natural forest for daily living. Community members at both sites have continually participated in the plantation of seedlings during the restoration process. Along with the establishment of nurseries, other activities related to natural resource management have also been carried out. These included environmental education and the establishment of a forest patrol program. In terms of environmental education, the MBG team has partnered with the school districts at both sites to incorporate environmental classes that educate students about their environment and the benefits of conserving it into the school program. In parallel, for adults, meetings were held at both sites that focused on increasing the awareness and importance of the sustainable use of natural resources. In the establishment of the forest patrol program, the MBG staff incorporated community members into caring and protecting the forest and its surroundings. The presence of forest agents around and inside the forest has been identified as a major contributor to the decrease in forest destruction at both sites.

With respect to socio-economic development, income-generating and healthcare-improving activities have been established. For example, at both sites, infrastructure such as wells and fountains aimed at fighting water borne disease were constructed. community members were also educated about vegetable gardens, as well as agricultural techniques to improve annual yields in rice farming. This education has not only improved diets and income levels within the communities, but has also decreased parti- 
cipation in activities that are detrimental to the forest. For example, in Ambalabe, participation in hill rice farming, a major contributor to deforestation, has decreased due to community education on alternative agricultural techniques. These activities were implemented to serve both the MBG's conservation efforts as well as the communities' economic interests by providing community members with alternative ways of making a living without compromising forest conservation. The positive results of these activities can be attributed to the CBC strategy's emphasis on the community's socio-economic concerns.

LEGITIMACY IN AMBALABE AND MAHABO. For organizations

to build trust in their respective environments, constituents in those environments must first grant the organization moral and pragmatic legitimacy. This can only be done in the context of the local institutional norms of the environment. In the case of MBG in Mahabo and Ambalabe, moral legitimacy was granted after the MBG staff showed respect to the community leaders by greeting and explaining the objectives of MBG before implementing any activities. This is a norm within the local institutional environments of both sites, thus allowing community leaders to scrutinize MBG as morally acceptable and granting MBG moral legitimacy. Then, the previously discussed workshops conducted and subsequent activities helped to build MBG's pragmatic legitimacy within the communities. The workshops were a way to communicate the practical benefits of MBG's activities to the communities, thus allowing community members to scrutinize MBG as practically beneficial to the community. Once a relationship was established, MBG began to implement strategies that tackled the socio-economic concerns of the community (i.e., educational programs, nurseries, etc.). After receiving the benefits of MBG's activities, community members began to grant MBG pragmatic legitimacy. Increasing moral and pragmatic legitimacy allowed the MBG staff to build trust in the community. Specifically, after the initial conversations and workshops, MBG could build trust through the continuation of CBC-related activities. This contributed to the community's expectation of positive outcomes that could be received from MBG, therefore further building community trust. This trust ultimately leads to cognitive legitimacy.

After many months of observing MBG's activities in the communities, the spiritual and community leaders at each site granted their full acceptance of MBG as a part of their community, thus granting MBG cognitive legitimacy. This acceptance was declared in the form of a traditional ceremony or fomban-drazana in front of all community members and the spirits of the ancestors at both sites. The ceremonies at the sites were an indication that MBG has gained cognitive legitimacy because it symbolized MBG's full integration into the community.

Since CBC success is the effectiveness of a CBC strategy in meeting the interests of local people while simultaneously meeting the conservation goals of the implementing organization, it can be stated that MBG achieved CBC success in both Ambalabe and Mahabo. An example of this success is reflected in MBG's basket weaving activity in Mahabo. Weaving baskets is an activity that women in Mahabo partake in for extra income. The women weave baskets throughout the week and sell the baskets at the Mahabo market day on Saturdays. Between 2003 and 2007, the price of each basket was roughly between $\$$ US0.5-1. During this period, the price was controlled by distributors who purchased the baskets from the weavers to sell in larger markets, thus leav- ing the women at the mercy of the distributors' prices. Aware of this situation, the MBG team sought out to find a solution where women can directly sell their baskets to a larger market, and cut out the distributors. The solution was a partnership between the MBG and the Blessing Basket Project, an organization that specifically connects basket weavers from developing countries to buyers in developed countries (Blessing Basket Project 2017). With this partnership, the women of Mahabo created an association of weavers and were able to sell their baskets in the US market. This largely increased the profit margin for the baskets, and contributed to the improvement of the Mahabo community's living standards. As a result, the women's association established a rule for itself stating that if any relative of a weaver member of their association is caught destroying the forest, the weaver is banned from the association and her baskets are no longer to be sold through the Blessing Basket Project. In this example, it can be stated that MBG achieved some $C B C$ success because the $C B C$ strategy served to meet the economic interests of the local people as well as the conservation interests of MBG.

Overall, from the perspective of the first author (A.R.) who has been part of these projects from their inception, the MBG has gained legitimacy and influenced community attitudes by implementing CBC strategies in Ambalabe and Mahabo. These efforts have not only improved the community members' standards of living, but have also helped achieve some conservation success. For example, in Ambalabe, since the MBG's involvement in this community in 2005, the number of native species seedlings planted has considerably increased, the number of annual trees cut down have decreased, the number of lemur traps have decreased, the area of forest that is lost to shifting cultivation has decreased, and the area of restored forest has increased (Table 1).

The perspective of the first author, although valuable, however, cannot be discussed as empirical evidence to support the hypotheses. Therefore, we empirically test our hypotheses on the relationships between the dimensions of legitimacy, trust, and attitudes in these two sites, as discussed in the following section.

\section{METHODS}

DATA COLLECTION. In May 2016, we collected survey data and followed the ethical standards of the National Institute of Health's (NIH) ethical standards for human research. These standards include respect for persons by treating individuals as autonomous agents; beneficence by respecting individual decisions and protecting people from harm; and justice by selecting participants equitably ( $\mathrm{NHH}$ 2008). It is important to note that an author of this paper has completed the CITI (Collaborative Institu-

Table 1. Conservation statistics in Ambalabe (2005-2016) according to MBG staff.

\begin{tabular}{|c|c|c|c|c|c|}
\hline year & $\begin{array}{l}\text { number of native } \\
\text { species seedling } \\
\text { planted }\end{array}$ & $\begin{array}{l}\text { restored } \\
\text { area (ha) }\end{array}$ & $\begin{array}{l}\text { area of forest } \\
\text { lost to shifting } \\
\text { cultivation (ha) }\end{array}$ & $\begin{array}{l}\text { number of } \\
\text { lemur traps }\end{array}$ & $\begin{array}{l}\text { number of } \\
\text { trees cut }\end{array}$ \\
\hline 2005 & no data & no data & 10 & 20 & 100 \\
\hline 2006 & 140 & 0.09 & 8 & 15 & 98 \\
\hline 2007 & 1791 & 1.12 & 4 & 5 & 30 \\
\hline 2008 & 7720 & 4.83 & 6 & 1 & 10 \\
\hline 2009 & 10644 & 6.65 & 4.5 & 2 & 10 \\
\hline 2010 & 3648 & 2.30 & 2 & 1 & 20 \\
\hline 2011 & 5070 & 3.17 & 0 & 0 & 5 \\
\hline 2012 & 3619 & 2.53 & 1 & 1 & 10 \\
\hline 2013 & 5271 & 3.60 & 2.5 & 4 & 15 \\
\hline 2014 & 12361 & 7.73 & 3 & 0 & - \\
\hline 2015 & 4228 & 2.64 & 0 & 0 & 5 \\
\hline 2016 & 6541 & 4.08 & 0 & 5 & 7 \\
\hline
\end{tabular}


tional Training Initiative) Program's basic course in social/behavioural research for investigators and key personnel.

To adhere to the $\mathrm{NIH}^{\prime} \mathrm{s}$ standards, we first discussed the scope of the data collection with MBG's field botanists and site facilitators at each site. It was recommended that we should recruit respectable members of each community to administer the surveys to ensure respect and beneficence for the respondents. Therefore, a local school director in Ambalabe and a university student who was home on vacation in Mahabo were recruited to administer the survey to community members. They were both compensated for their time and efforts. The survey administrators only took respondents who voluntarily agreed to participate in order to ensure the justice component of the NIH's ethical standards. Furthermore, no identifiable information was collected from any respondent in order to further ensure anonymity and confidentiality. Finally, the survey was placed in reverse causal order in order to reduce the threat of common methods bias (Lindell and Whitney 2001). These procedures not only ensured respect, anonymity, and justice for the respondents, but also reduced the risk of response biases in the survey responses.

The paper survey questionnaire was constructed to measure the latent constructs within the two communities. To measure trust, a scale that was developed by Garbarino and Johnson (1999) was utilized. This scale had 4 statements and asks the respondent to rank their agreement on a likert type scale from 1 (strongly disagree) to 7 (strongly agree). This scale was selected because it aligns with the conceptual understanding of trust within the context of this current research. Specifically, Garbarino and Johnson's (1999) describe trust as a constituent having an expectation of positive outcomes that can be received from an organization; this includes the measurement items that ask the respondent if the organization meets their expectations, and if they can count on the organization to be good in order to measure this construct. Similarly, we used Wang et al.'s (2012) scale to measure attitudes because the measurement items in this scale reflect this paper's conceptual understanding that attitudes are summary evaluations of an organization. Both scales for trust and attitudes were implemented in the context of MBG. Table 2 displays the measurement items for each scale. The items for each dimension of legitimacy were derived from Suchman's (1995) theoretical description of each dimension. As pragmatic legitimacy concerns the tangible benefits to the individual constituent, the constituent's community, and the constituent's larger society, items for each of these elements were asked to measure the latent construct which represents pragmatic legitimacy. It is important to note that since legitimacy is an overall evaluation of the organization and the organization's activities, we do not frame the question items into the context of specific activities, but instead ask the respondents to provide their feedback on MBG's overall activities.

Moral legitimacy was measured with two items which ask the respondents if they felt whether MBG was honest and decent. Both are elements mentioned by Suchman (1995) to describe moral legitimacy. Finally, cognitive legitimacy was measured with three items which ask the respondents if they felt that MBG was a permanent part of their society, a necessary part of their society, and an inevitable part of their society. These items are all highlighted as elements of cognitive legitimacy by Suchman (1995). To make the questions more understandable by the local community, the survey questionnaire was translated to Malagasy by MBG staff members who speak both English and Malagasy. Specifically, the principal investigators in this research consulted with field botanists and site facilitators at each site to ensure that the conceptual understanding of the question items asked in the local dialect reflected the scientific meaning of each construct. The experienced field botanists and site facilitators consulted have been working within these communities in implementing CBC efforts of the MBG for five or more years. Community members administered the survey to respondents. The recruited individuals verbally asked each question item to individual community members and recorded their answers on a likert type scale ranging from 1 (strongly agree) to 7 (strongly disagree).

Although precautions were taken to ensure the survey responses were not distorted by the methods utilized, certain limitations still apply to this data collection method. First, even though the survey was structured in reverse causal order, the threat of common methods bias in never void is any survey questionnaire. second, since the survey responses were collected from community members who voluntarily participated in the study, the sample is at risk of possibly under-representing some demographic groups within the communities; however, with this stated, anonymity and a willingness to participate in the survey was important to ensure the justice component of the $\mathrm{NIH}^{\prime} \mathrm{s}$ standards.

DATA ANALYSIS. The analyses were conducted in four stages.

First, a measurement assessment of the items and constructs were conducted. Second, the relationships between the constructs were tested in a structural model by employing partial least squares (PLS), using SmartPLS 2.0 (Ringle et al. 2005). Third, the relationships were also tested in a hierarchical regression model conducted in SPSS 19 to provide further evidence for the model. Finally, a mediation analysis utilizing the Preacher and Hayes (2004) mediation test was conducted to provide evidence of the mediating role that cognitive legitimacy plays in the relationship between trust and attitudes.

In the first stage, we assessed the measurement model using SmartPLS 2.0 (Ringle et al. 2005). We examined factor loadings, composite reliability, and average variance extracted (AVE) estimates to assess the validity and reliability of the latent constructs. Carmines and Zeller (1979) suggest that factor loadings should be close to or above .70 to ensure construct validity; Anderson and Gerbing (1988) suggest that the composite reliability estimates should exceed .70 to ensure reliability; and Fornell and Larcker (1981) suggest that the AVE for all constructs should exceed .50 to ensure convergent validity. We utilized these thresholds to ensure the measurement model sufficiently reflected the latent constructs that were measured. Furthermore, we also examined the construct correlations, means, and standard deviations for each construct to ensure discriminant validity.

Similar to the measurement assessment, we tested the hypotheses utilizing PLS in SmartPLS 2.0 during the second stage of the analyses. We selected PLS as the appropriate method because PLS is similar to regression, but it also concurrently models the structural paths. Also, the PLS algorithm allows for each indicator item to independently load onto the latent construct, where regressions would assume equal weights for all indicators (Magnusson et al. 2013). Furthermore, PLS can effectively handle smaller sample sizes for structural models (Hair et al. 2013).

In the third stage of the analyses, a hierarchical multiple regression was conducted in SPSS 19 with attitudes toward MBG as the dependent variable. This method was chosen to demonstrate 
the hierarchical nature of the model. Composite scores were calculated for each latent construct, and four regression models were conducted in this analysis.

In the final stage of the analyses, the Preacher and Hayes (2004) method of testing indirect effects was employed to test the mediating role that cognitive legitimacy plays in the relationship between trust and attitudes toward MBG. Where the PLS and regression analyses can show a hierarchical nature of the proposed relationships, this method tests for a specific mediating effect of cognitive legitimacy.

Table 2. Item loadings, composite reliability (CR), and average variance extracted (AVE); $\mathrm{N}=101$ (the questions in Malagasy are italicized)

\section{pragmatic legitimacy}

MBG's activities benefit me

CR/AVE loadings

Manome tombotsoa ahy ny asa ataon'i MBG

MBG's activities benefit the Ambalabe Commune

Manome tombotsoa ny Commune Ambalabe ny asa

ataon'i $M B G$

MBG's activities benefit Madagascar

Manome tombotsoa an'i Madagascar ny asa ataon'i

$M B G$

moral legitimacy

$.94 / .88$

MBG is honest

$M B G$ dia mendripitokisana

MBG is decent

MBG dia hendry

cognitive legitimacy

MBG is a permanent part of Ambalabe

MBG dia rantsana na ampahany iray maharitra ao Ambalabe

$M B G$ is a necessary part of Ambalabe

Tena ilain'ny Commune Ambalabe i MBG

MBG is an inevitable part of my community

MBG dia ampahany na rantsana tsy azo ialan'ny

fiarahamoniko

trust in MBG

MBG always meets my expectations

MBG dia mitondra ireo zavatra mifanaraka amin'ny eritreretiko na antenaiko

I can count on MBG to be good

Mahatoky zaho fa fikambanana na sehatr'asa tsara i

MBG

$M B G$ is reliable

Azo hianteherana i $M B G$

MBG can be trusted

Azo atokisana i $M B G$

attitude towards MBG

$.88 / .71$

supporting MBG is a Good Decision

Ny fanohanana an'i MBG dia fanaoahankevitra tsara

$M B G$ is a satisfactory organization

MBG dia fikambanana na sehetr'asa mahafapo

I can get a lot of benefits from supporting MBG

hahazoako tombontsoa betsaka ny fanohanana an'i $M B G$

Table 3 Construct correlations, means, and standard deviations of each construct. The values represent the strength of the correlation between the variables. Significance levels are represented by: ${ }^{*} p<.05,{ }^{* \star} p<.01,{ }^{* \star *} p<.001$.

\begin{tabular}{lccccc}
\hline & $\begin{array}{c}\text { pragmatic } \\
\text { legitimacy }\end{array}$ & $\begin{array}{c}\text { moral } \\
\text { legitimacy }\end{array}$ & $\begin{array}{c}\text { cognitive } \\
\text { legitimacy }\end{array}$ & $\begin{array}{c}\text { attitudes } \\
\text { trust } \\
\text { toward MBG }\end{array}$ \\
\hline pragmatic legitimacy & 1 & & & & \\
moral legitimacy & $0.57^{\star * *}$ & 1 & & & \\
cognitive legitimacy & $0.81^{\star * *}$ & $0.71^{* * *}$ & 1 & & \\
trust & $0.70^{\star * *}$ & $0.81^{* * *}$ & $0.73^{* * *}$ & 1 & \\
attitudes toward MBG & $0.71^{\star * *}$ & $0.77^{* * *}$ & $0.80^{* * *}$ & $0.84^{* * *}$ & 1 \\
mean & 5.95 & 5.39 & 5.65 & 5.63 & 5.58 \\
standard deviation & 1 & 1.26 & 1.09 & 1.19 & 1.31 \\
\hline
\end{tabular}

\section{RESULTS}

The data collection method yielded 50 responses from Ambalabe community members and 51 responses from Mahabo for a total of 101 usable responses. The mean age for the sample was 31.4 years old, with a standard deviation of 8.66 years. The sample consisted of roughly $57 \%$ male and $43 \%$ female respondents.

Results from the first stage of the analysis (Table 2, Table 3) indicated that the measurement model displayed validity and reliability as all factor loadings were above .70 , composite reliability estimates for each construct exceeded .70, and the AVE for each construct exceeded .50 .

In the second stage, results from the PLS model estimation provided strong support for the hypotheses. In support of hypothesis $H 1$, both moral $(\beta=.61, p<.001)$ and pragmatic $(\beta=.36$, $p<.001)$ legitimacy were found to positively influence community trust. In support of hypothesis $\mathrm{H} 2$, community trust $(\beta=.75$, $p<.001$ ) was found to significantly influence cognitive legitimacy. Finally, in support of hypothesis $H 3$, cognitive legitimacy $(\beta=.80$, $p<.001$ ) was found to positively influence attitudes toward MBG (Figure 3).

In the third stage of the analyses, results from the regression models provide support for the statement that both organizational legitimacy and trust are significant for the development of positive attitudes toward the organization (Table 4). In Model 1, the control variables of age and gender were included as variables, and age $(\beta=.17, p<.10)$ was found to marginally influence attitudes toward MBG while gender was not found to be significant. In Model 2 , pragmatic $(\beta=.40, p<.001)$ and moral $(\beta=.54, p<.001)$ legitimacy were added as predictors along with the control variables and were both found to be significant predictors of attitudes, while the control variables were not significant. In Model 3 , trust $(\beta=.51$, $p<.001)$ was included and was found to highly influence attitudes. When trust was added, both pragmatic $(\beta=.22, p<.01)$ and moral $(\beta=.22, p<.05)$ decreased in significance and beta, while age $(\beta=.10, p<.10)$ was marginally significant and gender was not sig-

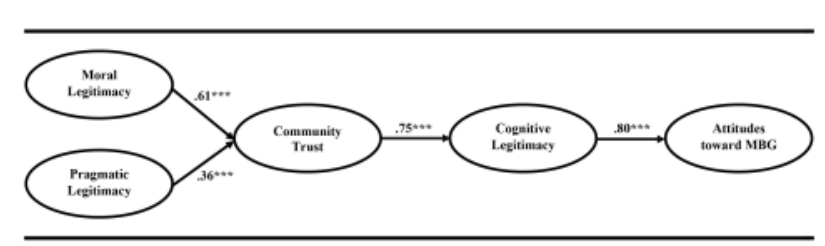

Figure 3. Structural model results for the partial least squares (PLS) estimation. Betas represent the variance in the dependent variable explained by the predictor variable. Significance levels are represented by: ${ }^{\star} p<.05,{ }^{*} p<.01$, $\star * * p<.001$

Table 4. Results of hierarchical multiple regression analysis: the influence of legitimacy and trust on attitudes toward the organization. Model 1 shows the influence of the control variables only, model 2 includes pragmatic and moral legitimacy, model 3 includes trust, and model 4 includes cognitive legitimacy. Significance levels are represented by: $\uparrow p<.10,{ }^{*} p<.05,{ }^{* *} p<.01,{ }^{* *} p<.001$.

\begin{tabular}{|c|c|c|c|c|c|c|c|c|}
\hline & \multicolumn{2}{|c|}{ model 1} & \multicolumn{2}{|c|}{ model 2} & \multicolumn{2}{|c|}{ model 3} & \multicolumn{2}{|c|}{ model 4} \\
\hline & & std. & & std. & & std. & & std. \\
\hline & $\beta$ & err. & $\beta$ & err. & $\beta$ & err. & $\beta$ & err. \\
\hline cognitive legitimacy & - & - & - & - & - & - & $0.40^{\star \star \star}$ & 0.11 \\
\hline trust & - & - & - & - & $0.51 * * *$ & 0.11 & $0.49 * * *$ & 0.10 \\
\hline pragmatic legitimacy & - & - & $0.40 * * *$ & 0.09 & $0.22^{* *}$ & 0.09 & -0.02 & 0.11 \\
\hline $\begin{array}{l}\text { moral legitimacy } \\
\text { control variables }\end{array}$ & - & - & $0.54^{* * *}$ & 0.07 & $0.22^{*}$ & 0.09 & 0.10 & 0.09 \\
\hline age & $0.17 \dagger$ & 0.02 & 0.04 & 0.01 & $0.10 \dagger$ & 0.01 & $0.09+$ & 0.01 \\
\hline gender & 0.06 & 0.27 & 0.00 & 0.15 & -0.03 & 0.13 & -0.08 & 0.13 \\
\hline adjusted R-square & 0.01 & & 0.70 & & 0.76 & & 0.80 & \\
\hline R-Square & 0.03 & & 0.71 & & 0.77 & & 0.81 & \\
\hline R-Square change & 0.03 & & $0.68^{* * *}$ & & $0.06 * * *$ & & $0.04 * * \star$ & \\
\hline
\end{tabular}


nificant. Finally, in Model 4, cognitive legitimacy ( $\beta=.40, p<.001$ ) was included and was found to highly predict attitudes. Also, in Model 4 , trust $(\beta=.49, p<.001)$ had a decreased beta, neither pragmatic nor moral were significant, age was found to be marginally significant $(\beta=.09, p<.10)$, and gender was found to not be significant. The overall hierarchical regression analysis yielded a significant model $[F(1,92)=18.34, p<.001$, R squared $=.81$, Adjusted $\mathrm{R}$ squared $=.80$ ].

The results of the hierarchical regression analysis provided evidence in support for the proposed model, as shown in Table 4. specifically, when trust was included in Model 3, pragmatic and moral legitimacy became less significant and had smaller beta values; and when cognitive legitimacy was included in Model 4, not only were trust and cognitive legitimacy found to be highly significant, but pragmatic and moral legitimacy were no longer significant. This indicates the mediating roles of trust and cognitive legitimacy in the model.

Although the PLS and regression analyses provide some indication of the mediating role of cognitive legitimacy in the relationship between trust and attitudes, it cannot be stated with ful confidence that cognitive legitimacy is a mediator from the results of these analyses. Specifically, in the regression analysis, attitudes toward MBG was the dependent variable, therefore, only the effects of the variables on this dependent variable was shown, which provides little evidence of mediation. Therefore, the Preacher and Hayes (2004) mediation test with 5000 bootstraps was conducted in SPSS 19 to test the mediating effect cognitive legitimacy. The results show that the indirect effect of trust on attitudes toward MBG with cognitive legitimacy as the mediator is significant with $99 \%$ confidence interval. Further, the relationship between trust and attitudes toward MBG was highly significant without the mediator $(\beta=.66, p<.001)$, and marginally significant when the mediator was inserted $(\beta=.16, p<.10)$ (Table 5). This provides evidence for the mediating role that cognitive legitimacy plays in the relationship between trust and attitudes toward MBG.

\section{DISCUSSION}

In this research, we find that (i) moral legitimacy influences community trust, (ii) pragmatic legitimacy influences community trust, (iii) community trust influences cognitive legitimacy, and (iv) cognitive legitimacy influences attitudes toward the organization (MBG). These findings emphasize the notion of Pretty and Smith (2004) that building social capital is important when organizations seek positive biodiversity outcomes. Thus, these findings provide strategic implications for organizations seeking to implement the $\mathrm{CBC}$ approach within their respective conservation sites.

By finding that both moral and pragmatic legitimacy influence trust, we imply that in order for organizations to gain trust within a community, it must first appeal to the community members as a morally good organization and/or must demonstrate the practical benefits it can provide to the community. Moral standards here are defined by the institutional environment, so the community scrutinizes what is morally acceptable. For example, in order for MBG to gain moral legitimacy in Mahabo and Ambalabe, the MBG staff met with community leaders to explain and discuss their interests and plans. This is a local institutional norm within these communities, and influenced moral legitimacy. In other words, the institutional environment includes informal norms of behaviour (Berkes 2004), and the communities of Ambalabe and Mahabo have specific norms which are considered by the community members to be appropriate behaviour for moral organizations. In MBG's case, to be considered a moral organization and increase moral legitimacy, the MBG staff followed the norm of first meeting with community leaders to discuss the MBG's interests.

Along with providing inference that moral and pragmatic legitimacy influence trust, the results from the PLS analyses also indicate that moral legitimacy has a stronger influence on trust than pragmatic legitimacy. This is an interesting result since trust is conceptualized as an expectation of positive outcomes (Bhattacharya et al. 1998), and pragmatic legitimacy is the constituent's perception that an organization can provide tangible benefits. However, moral legitimacy is a positive normative evaluation of an organization and may better influence an expectancy of positive outcomes than pragmatic legitimacy. This point, however, requires further research, and we encourage future researchers to further investigate this dynamic.

The practical implication of the finding that both pragmatic and moral legitimacy influence trust is valuable to organizations such as the MBG which rely on building trust through $\mathrm{CBC}$ strategies. Strategically, this finding implies initially gaining moral and pragmatic legitimacy is beneficial to organizations seeking to build trust with a community. Also, although both moral and pragmatic legitimacy can influence trust, the finding that moral legitimacy has a stronger influence on trust than pragmatic legitimacy implies that establishing moral legitimacy is a better trust-building strategy than establishing pragmatic legitimacy. The contribution of this finding to $\mathrm{CBC}$ research revolves around the notion that moral and pragmatic legitimacy can be added to elements of organizational trust-building. Previous research suggests that community engagement and interactions are crucial to building trust (Davenport et al. 2007). Our finding suggests that to build trust, community engagement and interactions should reflect the organization's practical and moral benefits to the community. Examples of these activities include recognizing and integrating community capabilities into activities, exchanging ideas with community members, and respecting community members as equals,

Table 5. The Preacher-Hayes mediation test results: the mediating effect of cognitive legitimacy on the relationship between trust and attitudes toward MBG. The indirect and direct effects with significance levels represented by: $t p<.10$, ${ }^{*} \mathrm{p}<.05,{ }^{* *} \mathrm{p}<.01,{ }^{* *} \mathrm{p}<.001$

\begin{tabular}{|c|c|c|c|c|}
\hline \multirow{3}{*}{ direct and total effects } & \multirow[b]{2}{*}{$\beta$} & \multirow[b]{2}{*}{ std. err. } & \multirow[b]{2}{*}{ t-value } & $\mathrm{Cl}(95 \%)$ \\
\hline & & & & lower upper lower upper \\
\hline & & & & \\
\hline trust -> cognitive legitimacy & $0.67 * * *$ & 0.06 & 10.75 & \\
\hline cognitive legitimacy -> attitudes toward MBG & $0.74^{* * *}$ & 0.09 & 8.31 & \\
\hline trust -> attitudes toward MBG (without mediator) & $0.66^{* * *}$ & 0.07 & 9.07 & \\
\hline $\begin{array}{l}\text { trust -> attitudes toward MBG (with mediator) } \\
\text { indirect effects }\end{array}$ & $0.16 \dagger$ & 0.08 & 1.91 & \\
\hline trust $->$ cognitive legitimacy $->$ attitudes toward MBG & & & & 0.3080 .6900 .2620 .759 \\
\hline
\end{tabular}


as the MBG has done in their respective communities. These activities should be conducted with the perspective that the community is a group of socially interdependent people who are governed by the institutions of the environment. For example, before any conservation activities were conducted, the MBG staff in Ambalabe and Mahabo held workshops in order to better understand the needs of the community as well as communicate MBG's goals and benefits to community members within the institutional environments.

The second finding of this current research is that community trust precedes cognitive legitimacy, which reinforces the crucia role that trust plays in CBC strategy success. This finding indicates that before organizations can be accepted by community members as a permanent and inevitable part of their environment, they must first build trust. Thus, trust plays a mediating role between pragmatic/moral legitimacy and cognitive legitimacy. As evidenced in MBG's case in Mahabo and Ambalabe, before gaining complete acceptance in the community (cognitive legitimacy), the MBG established relationships with the community members through workshops and $\mathrm{CBC}$-related activities in order to build trust. By gaining this trust, MBG was able to be accepted as a permanent part of the environment.

The finding that cognitive legitimacy mediates the relationship between trust and attitudes toward the organization indicates that organizations could indirectly influence community attitudes by building trust and cognitive legitimacy. This finding is crucial to CBC strategy success because attitudes are pre-dispositions to behaviour (Bagozzi 1992). As previously mentioned, the theory of reasoned action emphasizes the hierarchical nature of the relationship between attitudes and behaviour (Ajzen and Madden 1986). Organizations seeking to influence behaviours that promote conservation must first influence attitudes, but in order to influence attitudes, cognitive legitimacy must be gained from the community. Since the successes of CBC strategies rely on conservation-promoting behaviours, this finding proves to be an important finding in conservation strategic management. This strategic implication was evidenced in MBG's success at reaching the conservation success through the CBC method, as gaining cognitive legitimacy influenced positive attitudes towards MBG's activities. This was evidenced through community participation in conservation initiatives such as forest patrolling, and the previously discussed women's weaving association's rule that the forest must not be cut.

In conclusion, we have introduced three dimensions of organizational legitimacy as important elements in understanding of trust and attitudes toward an organization. The findings provide support for a framework which states that pragmatic and moral legitimacy precede trust, trust influences cognitive legitimacy, which influences downstream attitudes. The findings of this research suggest that organizational legitimacy plays a key role in the success of $\mathrm{CBC}$ strategies, and we invite future research to further explore these relationships.

\section{ACKNOWLEDGEMENTS}

We want to extend gratitude to the local community members of Ambalabe and Mahabo for kindly responding to the survey questions. We give our special thanks to T. Pierre, the Principal of the secondary school in the Ambalabe village and T. T. Barijaoana, Senior student at the School of Social Science of the Fianarantsoa University for conducting the survey. Also, we want to express our gratitude to all MBG staff in Madagascar, especially R. Ludovic and L. Rasoaviety, site facilitators at Mahabo and Ambalabe respectively, for assisting in conducting the survey at the two sites. We would like to thank R. W. Bussmann for his help in reviewing this research. Finally, we would like to thank M. Blomberg for his assistance in creating the figures for this paper.

\section{REFERENCES}

Ajzen, I. and Fishbein, M. 1980. Understanding Attitudes and Predicting Social Behaviour. Prentice-Hall, Englewood Cliffs, New Jersey.

Ajzen, I. and Madden, T. J. 1986. Prediction of goal-directed behavior: attitudes, intentions, and perceived behavioral control. Journal of Experimental Social Psychology 22, 5: 453-474. (doi:10.1016/0022-1031(86)90045-4)

Allard, S. W. and Small, M. L. 2013. Reconsidering the urban disadvantaged the role of systems, institutions, and organizations. The Annals of the American Academy of Political and Social Science 647, 1: 6-20. (doi:10.1177/0002716213479317)

Anderson, J. C. and Gerbing, D. W. 1988. Structural equation modeling in practice: A review and recommended two-step approach. Psychological Bulletin 103, 3: 411-423. (doi:10.1037/0033-2909.103.3.411)

Andriaholinirina, N., Baden, A., Blanco, M., Chikhi, L., Cooke, A., et al. 2014. Eulemur cinereiceps 2014. The IUCN Red List of Threatened Species: e.T8205A16116926. (doi:10.2305/IUCN.UK.2014-1.RLTS.T8205A16116926.en)

Andriamaharoa, H., Birkinshaw, C. and Reza, L. 2010. Day-time feeding ecology of Eulemur cinereiceps in the Agnalazaha Forest, Mahabo-Mananivo, Madagascar. Madagascar Conservation \& Development 5, 1: 55-63. (doi:10.4314/mcd.v5i1.57341)

Bagozzi, R. P. 1992. The self-regulation of attitudes, intentions, and behavior. Social Psychology Quarterly 55, 2: 178-204. (doi:10.2307/2786945)

Bellah, R. N., Madsen, R., Sullivan, W. M., Swidler, A. and Tipton, S. M. 1985. Habits of the Heart: Individualism and Commitment in American Life. Harper and Row, New York.

Berkes, F. 2004. Rethinking community-based conservation. Conservation Biology 18, 3: 621-630. (doi:10.1111/j.1523-1739.2004.00077.x)

Berkes, F. 2007. Community-based conservation in a globalized world. Proceedings of the National Academy of Sciences of the United States of America 104, 39: 15188-15193. (doi:10.1073/pnas.0702098104)

Bhattacharya, R., Devinney T. M. and Pillutla, M. M. 1998. A formal model of trust based on outcomes. Academy of Management Review 23, 3: 459-472. (doi:10.5465/AMR.1998.926621)

Blessing Basket Project. <http://www.blessingbasket.org/about-us/> accessed 3 February 2017

Brooks, J., Waylen, K. A. and Mulder, M. B. 2013. Assessing community-based conservation projects: a systematic review and multilevel analysis of attitudinal, behavioral, ecological, and economic outcomes. Environmental Evidence 2, 2: 1-34. (doi:10.1186/2047-2382-2-2)

Campbell, L. M. and Vainio-Mattila, A. 2003. Participatory development and community-based conservation: opportunities missed for lessons learned? Human Ecology 31, 3: 417-437. (doi:10.1023/A:1025071822388)

Campbell, J., Eden, L. and Miller, S. 2012. Multinationals and corporate social responsibility in host countries: does distance matter? Journal of International Business Studies 43, 1: 84-106. (doi:10.1057/jibs.2011.45)

Carmines, E. G. and Zeller, R. A. 1979. Reliability and Validity Assessment. Sage Publications Incorporated, Thousand Oaks, California.

Consiglio, T., Schatz, G. E., Mcpherson, G., Lowry II, P. P., Rabenantoandro, J., et al. 2006. Deforestation and plant diversity of Madagascar's littoral forests. Conservation Biology 20, 6: 1799-1803. (doi:10.1111/j.15231739.2006.00562.x)

Davenport, M. A., Leahy, J. E., Anderson, D. H. and Jakes, P. J. 2007. Building trust in natural resource management within local communities: a case study of the Midewin National Tallgrass Prairie. Environmental Management 39, 3: 353-368. (doi:10.1007/s00267-006-0016-1)

DiMaggio, P. J. and Powell, W. W. 1983. The iron cage revisited: institutional isomorphism and collective rationality in organizational fields. American Sociological Review 48, 2: 147-160. (doi:10.2307/2095101) 
Dolch, R., Ndriamiary, J., Ratolojanahary, T., Randrianasolo, M. and Ramanantenasoa, I. A. 2015. Improving livelihoods, training para-ecologists, enthralling children: Earning trust for effective community-based biodiversity conservation in Andasibe, eastern Madagascar. Madagascar Conservation \& Development 10, 1: 21-28. (doi:10.4314/mcd.v10i1.S4)

Fornell, C. and Larcker, D. F. 1981. Evaluating structural equation models with unobservable variables and measurement error. Journal of Marketing Research 18, 1: 39-50. (doi:10.2307/3151312)

Frey, J. B. and Berkes, F. 2014. Can partnerships and community-based conservation reverse the decline of coral reef social-ecological systems? International Journal of the Commons 8, 1: 26-46. (doi:10.18352/ijc.408)

Fritz-Vietta, N. V. M., Röttger, C. and Stoll-Kleemann, S. 2009. Community-based management in two biosphere reserves in Madagascar - distinctions and similarities: what can be learned from different approaches? Madagascar Conservation \& Development 4, 2: 86-97. (doi:10.4314/mcd.v4i2.48648)

Garbarino, E. and Johnson, M. S. 1999. The different roles of satisfaction, trust, and commitment in customer relationships. The Journal of Marketing 63,2 : 70-87. (doi:10.2307/1251946)

Garud, R., Schildt, H. A. and Lant, T. K. 2014. Entrepreneurial storytelling, future expectations, and the paradox of legitimacy. Organization Science 25, 5: 1479-1492. (doi:10.1287/orsc.2014.0915)

Goldman, M. 2003. Partitioned nature, privileged knowledge: community-based conservation in Tanzania. Development and Change 34, 5: 833-862. (doi:10.1111/j.1467-7660.2003.00331.x)

Hackel, J. D. 1999. Community conservation and the future of Africa's wildlife. Conservation Biology 13, 4: 726-734. (doi:10.1046/j.15231739.1999.98210.X)

Hair, J. F., Hult, G. T. M., Ringle, C. M. and Sarstedt, M. 2013. A Primer on Partial Least Squares Structural Equation Modeling (PLS-SEM). Sage Publications, Thousand Oaks, California.

Harris, A. R. 2007. "To live with the Sea" development of the Velondriake community-managed protected area network, south west Madagascar. Madagascar Conservation \& Development 2, 1: 43-49. (doi:10.4314/239)

Harris, A. R. 2011. Out of sight but no longer out of mind: a climate of change for marine conservation in Madagascar. Madagascar Conservation \& Development 6, 1: 7-14. (doi:10.4314/mcd.v6i1.68058)

Husted, B. W., Montiel, I. and Christmann, P. 2016. Effects of local legitimacy on certification decisions to global and national CSR standards by multinational subsidiaries and domestic firms. Journal of International Business Studies 47, 3: 382-397. (doi:10.1057/jibs.2016.3)

IUCN 2016. The IUCN Red List of Threatened Species. Version 2016-3. Available at <http://www.iucnredlist.org >.

Johnson, C., Dowd, T. J. and Ridgeway, C. L. 2006. Legitimacy as a social process. Annual Review of Sociology 32: 53-78. (doi:10.1146/annurev.soc.32.061604.123101)

Kostova, T. and Zaheer, S. 1999. Organizational legitimacy under conditions of complexity: the case of the multinational enterprise. Academy of Management Review 24, 1: 64-81. (doi:10.5465/AMR.1999.1580441)

Lepp, A. and Holland, S. 2006. A comparison of attitudes toward state-led conservation and community-based conservation in the village of Bigodi, Uganda. Society and Natural Resources 19, 7: 609-623. (doi:10.1080/08941920600742377)

Lindell, M. K. and Whitney, D. J. 2001. Accounting for common method variance in cross-sectional research designs. Journal of Applied Psychology 86, 1: 114-121. (doi:10.1037/0021-9010.86.1.114)

Lowry, P. P., II, Schatz, G. E. and Phillipson, P. B. 1997. The classification of natural and anthropogenic vegetation in Madagascar. In: Natural Change and Human Impact in Madagascar. S. M. Goodman and B. D. Patterson (eds.), pp 93-123. Smithsonian Institution Press, Washington.

Magnusson, P., Westjohn, S. A., Semenov, A. V., Randrianasolo, A. A. and Zdravkovic, S. 2013. The role of cultural intelligence in marketing adaptation and export performance. Journal of International Marketing 21, 4: 44-61. (doi:10.1509/jim.13.0055)

MBG 2017. Missouri Botanical Garden. <http://www.missouribotanicalgarden.org > accessed 3 February 2017.
Mehta, J. N. and Heinen, J. T. 2001. Does community-based conservation shape favorable attitudes among locals? An empirical study from Nepal. Environmental Management 28, 2: 165-177. (doi:10.1007/s002670010215)

Meyer, J. W. and Rowan, B. 1977. Institutionalized organizations: formal structure as myth and ceremony. American Journal of Sociology 83, 2: 340-363. (doi:10.1086/226550)

Meyer, J. W. and Scott, W. R. 1983. Organizational Environments: Ritual and Rationality. Sage Publications, Beverly Hills, California.

Mintzberg, H. 1987. The strategy concept I: Five Ps for strategy. California Management Review, 30, 1: 11-24. (doi:10.2307/41165263)

$\mathrm{NIH}$ 2008. Protecting human research participants. NIH (National Institutes of Health) Office of Extramural Research: 37-108. Available at <https://phrp.nihtraining.com/users/PHRP.pdf>

Osei-Tutu, P., Pregernig, M. and Pokorny, B. 2014. Legitimacy of informal institutions in contemporary local forest management: insights from Ghana. Biodiversity and Conservation 23, 14: 3587-3605. (doi:10.1007/s10531-014-0801-8)

Owen-Smith, G. 1993. Wildlife conservation in Africa. In: Voices from Africa: Local Perspectives on Conservation. D. Lewis and N. Carter (eds.), pp 57-70. World Wildlife Fund, Baltimore.

Parker, I. S. C. 1983. Conservation, realism, and the future. In: Management of Large Mammals in African Conservation Areas. R. N. Owen-Smith (ed.), pp 281-290. Huam, Pretoria, South Africa.

Peng, M. W., Sun, S. L., Pinkham, B., and Chen, H. 2009. The institution-based view as a third leg for a strategy tripod. Academy of Management Perspectives 23, 3: 63-81. (doi:10.5465/AMP.2009.43479264)

Pirsch, J., Gupta, S. and Grau, S. L. 2007. A framework for understanding corporate social responsibility programs as a continuum: An exploratory study. Journal of Business Ethics 70, 2: 125-140. (doi:10.1007/s10551-006-9100-y)

Preacher, K. J. and Hayes, A. F. 2004. SPSS and SAS procedures for estimating indirect effects in simple mediation models. Behavior Research Methods, Instruments, \& Computers 36, 4: 717-731. (doi:10.3758/BF03206553)

Pretty, J. and Smith, D. 2004. Social capital in biodiversity conservation and management. Conservation Biology 18, 3: 631-638. (doi:10.1111/j.15231739.2004.00126.X)

Rabearivony, J. Fanameha, E., Mampiandra, J. and Thorstrom, R. 2008. Taboos and social contracts: tools for ecosystem management - lessons from the Manambolomaty Lakes RAMSAR site, western Madagascar. Madagascar Conservation and Development 3, 1: 7-16. (doi:10.4314/196)

Rakotomanana, H., Jenkins, R. K. B. and Ratsimbazafy, J. 2013. Conservation challenges for Madagascar in the next decade. In: Conservation Biology: Voices from the Tropics. N. P. H. Raven, S. Sodhi and L. Gibson (eds.), pp 33-39. John Wiley \& Sons, Ltd, Oxford.

Ringle, C. M., Wende, S. and Will, A. 2005. SmartPLS 2.0 M3. University of Hamburg, Hamburg.

Rovai, A. P. 2002. Building sense of community at a distance. The International Review of Research in Open and Distributed Learning 3, 1: 1-16. (doi:10.19173/irrodl.v3i1.79)

Salafsky, N., Cauley, H., Balachander, G., Cordes, B., Parks, J., et al. 2001. A systematic test of an enterprise strategy for community-based biodiversity conservation. Conservation Biology 15, 6: 1585-1595. (doi:10.1046/j.1523-1739.2001.00220.x)

Sandström, A., Crona, B. and Bodin, Ö. 2014. Legitimacy in co-management: the impact of preexisting structures, social networks and governance strategies. Environmental Policy and Governance 24, 1: 60-76. (doi:10.1002/eet.1633)

Scott, W. R. 1995. Institutions and Organizations. Sage Publications, Thousand Oaks, California.

Scott, W. R. 2008. Approaching adulthood: the maturing of institutional theory. Theory and Society 37, 5: 427-442. (doi:10.1007/s11186-008-9067-z)

Smetana, J. G. and Adler, N. E. 1980. Fishbein's value x expectancy model: an examination of some assumptions. Personality and Social Psychology Bulletin 6, 1: 89-96. (doi:10.1177/014616728061013) 
Suchman, M. C. 1995. Managing legitimacy: strategic and institutional approaches. Academy of Management Review 20, 3: 571-610. (doi:10.5465/AMR.1995.9508080331)

Waeber, P. O.,Wilmé, L., Ramamonjisoa, B., Garcia, C., Rakotomalala, D., et al. 2015. Dry forests in Madagascar: neglected and under pressure. International Forestry Review 17, 2S: 127-148. (doi:10.1505/146554815815834822)

Wang, M. C-H., Jain, M., Ming-Sung Cheng, J. and Kyaw-Myo Aung, G. 2012. The purchasing impact of fan identification and sports sponsorship. Marketing Intelligence \& Planning 30, 5: 553-566. (doi:10.1108/02634501211251052)

Waylen, K. A., Fischer, A., McGowan, P. J. K., Thirgood, S. J. and Milner-Gulland, E. J. 2010. Effect of local cultural context on the success of community-based conservation interventions. Conservation Biology 24, 4: 1119-1129. (doi:10.1111/j.1523-1739.2010.01446.x)

Western, D. and Wright, R. M. 1994. The background to community-based conservation. In: Natural Connections: Perspectives in Community-Based Conservation. D. Western, R. M. Wright and S. C. Strum (eds), pp 1-12. Island Press, Washington, D.C.

Wood, D. J. 1991. Corporate social performance revisited. Academy of Management Review 16, 4: 691-718. (doi:10.5465/AMR.1991.4279616) 